\title{
Method for residual strain modeling taking into account mold and distribution of heat transfer coefficients for thermoset composite material parts
}

\author{
Mikhail Kiauka $^{1}$ (D) $\cdot$ Mikhail Kasatkin $^{1}$ (D) - Iuliia Tcygantceva ${ }^{1}$ (D) Nikolai Efimov-Soini $^{1}$ (D) Alexey Borovkov $^{1}$ (D)
}

Received: 18 January 2021 / Accepted: 20 April 2021 / Published online: 6 July 2021

(C) The Author(s) 2021

\begin{abstract}
The article presents a technique for process-induced residual strain modeling for thermoset composite material parts. The model takes into account the mechanical and thermal contact between the part and the mold. The technique is implemented in the ABAQUS software using user subroutines. Using the technique, it is possible to clarify the distribution of the heat transfer coefficient on the surface of the part and mold using the CFD method. Distribution of heat transfer coefficients are obtained in ANSYS CFX under the appropriate process conditions. The method is verified for the U-shaped sample. Also, the results of modeling the stringer-stiffened curved composite panel using the developed technique without taking into account the mold and heat transfer coefficient distribution are presented.
\end{abstract}

Keywords Thermoset composite - Transient heat transfer - Heat transfer coefficient - Autoclave $\cdot$ Curing $\cdot$ Cure kinetics · Composite manufacturing $\cdot$ Shape distortion

\section{Introduction}

Products made of thermoset composite materials are widespread in the aviation, shipbuilding, automotive, energy, and other industries. The main methods for obtaining such materials are liquid composite molding (LCM) and autoclave molding. As a result of the technological process, various technological defects may appear. To reduce costs at the stage of development a manufacturing process, numerical modeling is used. In general, the textile reinforcement geometry,

Mikhail Kiauka

kiauka_myu@spbstu.ru

Mikhail Kasatkin

kasatkin.mm@edu.spbstu.ru

Iuliia Tcygantceva

tsygantseva.yuyu@edu.spbstu.ru

Nikolai Efimov-Soini

efimovs_nk@spbstu.ru

Alexey Borovkov

borovkov@spbstu.ru

1 Peter the Great St. Petersburg Polytechnic University, St. PetersburgPolytechnicheskaya, 29, Russia 195251 draping, impregnation, curing, residual stresses, and strains are modeled. Simulation captures effects such as fiber shear; the formation of air voids; incomplete curing zones; excessive residual stresses that can lead to the destruction of the part during the manufacturing process; and unplanned shape distortion of the part [1-3]. The general goal of our research is to take into account all stages of the manufacturing process to determine the final properties of the product, including physical and mechanical properties, residual stresses, and shape distortion. This article is focused on the determination of thermal boundary conditions and subsequent modeling of process-induced residual strains.

Works [4-6] examines the effect of a number of design and process parameters on spring-in by experimental methods. Also, the spring-in angle is determined from analytical and semi-empirical relationships. These formulas include inplane and through-thickness thermal and isothermal chemical shrinkage, temperature change, and initial angle. In [7-9], curing simulation methods is presented, when interaction between part and mold is imitated with using constraints. In [10-12], Svanberg studied three different boundary conditions: freestanding for imitation of mold which is very soft compared to the composite; fully constrained part for rigid mold imitation; and with frictionless contact conditions 
between part and mold. Thermal contact was not taken into account in these models. As will be shown below, thermal contact in the model significantly influences the simulation results. In [13] a coupled thermo-mechanical problem is modeled taking into account thermal and mechanical contact. Thermal contact is assumed to be ideal. In [14-16], friction coefficient during cure changes for mechanical contact. The state of composite material changes significantly during cure, from viscous to rubbery and then to stiff solid. Therefore, contact changes from stick behavior to slip behavior. Various approaches and aspects of cure modeling and process-induced strains are presented in [17-21].

In these works, two approaches to modeling a laminated composite are used. In the first case, a layer-by-layer approach is used, when one ply corresponds to one solid element in thickness. Otherwise, the averaged properties of the laminate are used. The averaging techniques are described in more detail in [22, 23].

In the works presented above, to simulate the heat transfer from the heated air of the oven/autoclave, convection boundary condition is used. For this, the sink temperature as a temperature cycle and constant typical heat transfer coefficient (HTC) on the open surface of the part and mold is set. In a real process, an uneven temperature and HTC distribution on the surface part occurs in an autoclave due to a complex air flow pattern. It is especially important to take this phenomenon into account to simulate for large-sized products of complex shape. For some of these thin-walled structures, increased requirements are imposed on shape accuracy (for example, antenna reflectors $[24,25])$ and the uneven distribution of HTC can significantly influence the accuracy of modeling residual strains. This fact is explained by influence of the HTC on the cure degree. Berdnikova et al. [26] studied uneven distribution temperature effect with using computational fluid dynamics (CFD) simulation. But material model in this research does not take into account the effect of resin chemical shrinkage. Airflow simulation and estimation of convection boundary conditions in autoclave are presented in [27-29].

Table 1 Resin parameters for KamalSourour model [21]

\begin{tabular}{lc}
\hline Parameters & Epoxy resin \\
\hline$m$ & 0.51 \\
$n$ & 1.49 \\
$A_{1}\left(\mathrm{~s}^{-1}\right)$ & 1528 \\
$A_{2}\left(\mathrm{~s}^{-1}\right)$ & 1.6 \\
$E_{\mathrm{a} 1}(\mathrm{~kJ} / \mathrm{mol})$ & 59.4 \\
$E_{\mathrm{a} 2}(\mathrm{~kJ} / \mathrm{mol})$ & 26.3 \\
$H_{\mathrm{T}}(\mathrm{kJ} / \mathrm{kg})$ & 198.9 \\
\hline
\end{tabular}

In this research, the above approaches are combined and a new technique for modeling a laminated composite taking into account thermal and chemical shrinkage, as well as mechanical and thermal contact with the mold is presented. Two ways of setting the HTC are used. First, the HTC is set the same for all surfaces of the part and mold. Then the HTC are obtained from CFD analysis in ANSYS CFX. In the CFD analysis, for the part and the mold, the airflow in an autoclave is simulated. The possibility of simplifying the problem to a stationary process and transfer of HTC to a finite element software package ABAQUS are also investigated. The goal of this research is to propose an engineering approach for shape distortion prediction taking into account these phenomena.

\section{Constitutive material model}

\subsection{Main relationships for thermal and mechanical behavior}

Transient Fourier anisotropic heat conduction equation, with a heat generation term from the exothermic resin cure reaction

$\rho \frac{\delta\left(C_{p} T\right)}{\delta t}=k_{i j} \nabla^{2} T+q$

Heat flux due to internal heat generation in a material

$q=\rho_{\mathrm{m}} H_{T}\left(1-V_{f}\right) \frac{\mathrm{d} X}{\mathrm{~d} t}$

In this research, Kamal-Sourour semi-empirical cure reaction formulation is used [30, 31]. It can be determined by examining heat flow measurements (e.g., from differential scanning calorimetry (DSC))

$\frac{\mathrm{d} \alpha}{\mathrm{d} t}=K(T) X^{m}(1-X)^{n}$

Table 2 Ply properties in rubbery and glassy state [12]

\begin{tabular}{lll}
\hline Property & Rubbery state & Glassy state \\
\hline$E_{1}, E_{2}(\mathrm{GPa})$ & 58.7 & 65 \\
$E_{3}(\mathrm{GPa})$ & 0.12 & 13 \\
$G_{12}(\mathrm{GPa})$ & 0.03 & 4.5 \\
$G_{23}, G_{13}(\mathrm{GPa})$ & 0.04 & 5 \\
$\nu_{12}$ & 0 & 0.03 \\
$\nu_{23}, \nu_{13}$ & 0.49 & 0.3 \\
$\alpha_{11}, \alpha_{22}\left(1 /{ }^{\circ} \mathrm{C}\right)$ & $-7.63 \cdot 10^{-8}$ & $2.5 \cdot 10^{-6}$ \\
$\alpha_{33}\left(1 /{ }^{\circ} \mathrm{C}\right)$ & $1.53 \cdot 10^{-4}$ & $7.2 \cdot 10^{-5}$ \\
$\beta_{11}, \beta_{22}\left(1 /{ }^{\circ} \mathrm{C}\right)$ & $-2.93 \cdot 10^{-6}$ & $-3.14 \cdot 10^{-4}$ \\
$\beta_{33}\left(1 /{ }^{\circ} \mathrm{C}\right)$ & $-8.9 \cdot 10^{-3}$ & $-8.9 \cdot 10^{-3}$ \\
\hline
\end{tabular}


Fig. 1 FE model and boundary conditions for a U-shaped part

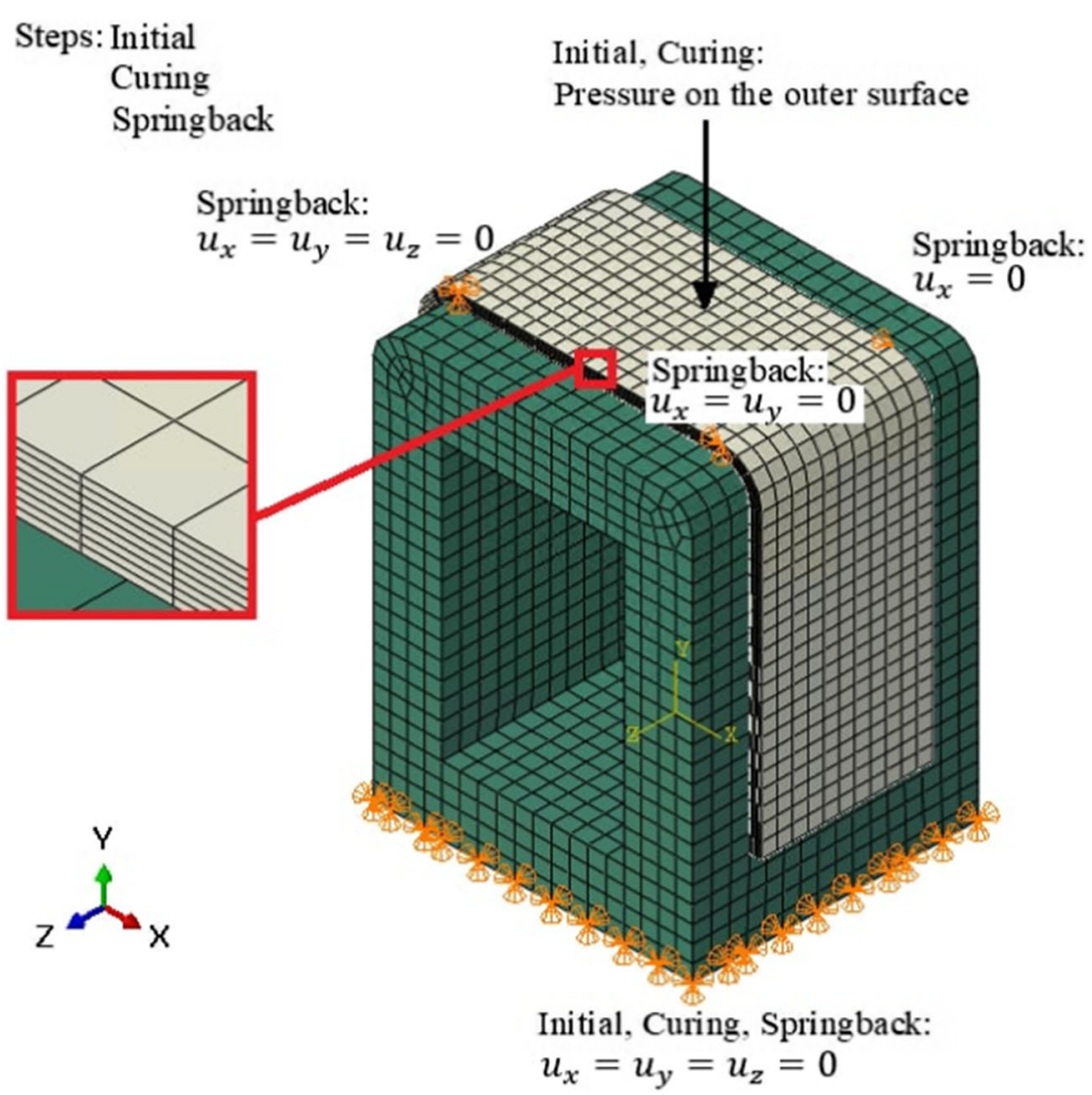

$K(T)=A \cdot \exp \left[\frac{-E_{\mathrm{a}}}{R T}\right]$

where $\boldsymbol{K}(\boldsymbol{T})$ is the Arrhenius-type relation for the reaction temperature dependency; $\boldsymbol{A}$ is the pre-exponential factor; $\boldsymbol{m}$ and $\boldsymbol{n}$ are model constants; $\boldsymbol{E}_{\mathbf{a}}$ is the apparent activation energy; $\boldsymbol{R}$ is the universal gas constant; and $\boldsymbol{T}$ is the temperature.

During cure, three states of the matrix are successively replaced-liquid, rubbery, and glassy. The process of curing the resin is associated with the appearance of a nonmechanical strains [22].

Nonmechanical strains represent the sum of strains from thermal expansion $\varepsilon_{i j}^{T}$ and from chemical shrinkage $\varepsilon_{i j}^{C}$ :

$\varepsilon_{i j}^{E}=\varepsilon_{i j}^{T}+\varepsilon_{i j}^{C}$.
Thermal strains are defined as:

$\varepsilon_{i j}^{T}=\int_{0}^{t} \alpha_{i j}(T, X) \frac{\partial T}{\partial t^{\prime}} \mathbf{d} t^{\prime}$,

where the instantaneous coefficients of thermal expansion $\alpha_{i j}$ depend on temperature and degree of cure as

$$
\alpha_{i j}=\left\{\begin{array}{cc}
\alpha_{i j}^{l}, & X<X_{\text {gel }} \quad \text { и } \quad T \geq T_{g}(X) \\
\alpha_{i j}^{r}, & X \geq \mathbf{X}_{\text {gel }} \quad \text { и } \quad T \geq T_{g}(X) \\
& \alpha_{i j}^{\mathrm{g}}, \quad T<T_{g}(\mathbf{X}) .
\end{array}\right.
$$

where $\alpha_{i j}^{l}$, $\boldsymbol{\alpha}_{i j}^{r}$, and $\boldsymbol{\alpha}_{i j}^{g}$ are linear coefficients of thermal expansion in the liquid, rubbery, and glassy states, respectively; $\boldsymbol{X}$ is the degree of cure; and $\boldsymbol{X}_{\mathrm{gel}}$ is the degree of cure at gelation.
Fig. 2 Stiffened composite curved panel FE model

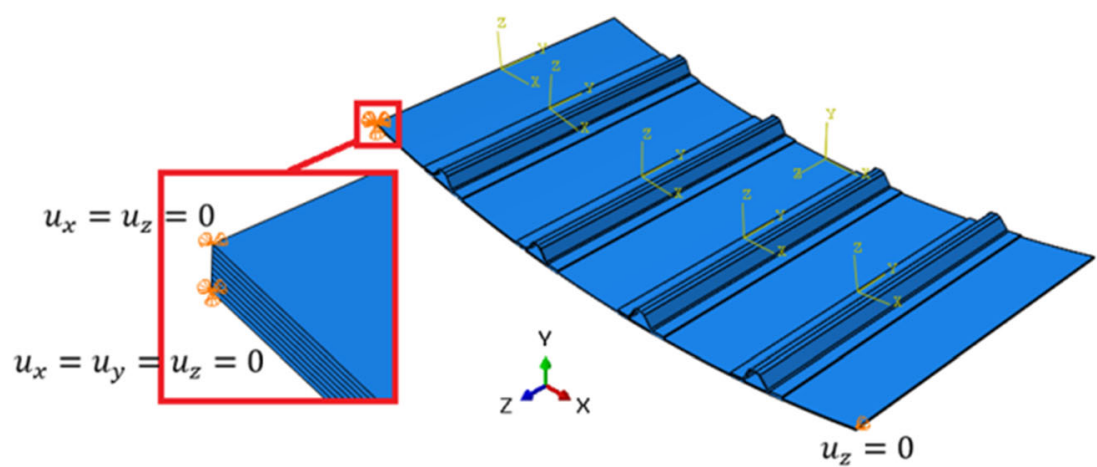


Chemical shrinkage is defined as

$\varepsilon_{\mathrm{ij}}^{\mathbf{C}}=\int_{0}^{\mathrm{t}} \beta_{\mathrm{ij}}(\mathbf{T}, \mathbf{X}) \frac{\partial \mathbf{X}}{\partial \mathbf{t}^{\prime}} \mathbf{d \mathbf { t } ^ { \prime }}$,

where the instantaneous coefficients of chemical shrinkage $\boldsymbol{\beta}_{\boldsymbol{i}}$ depend on temperature and degree of cure as,

$$
\boldsymbol{\beta}_{\mathrm{ij}}=\left\{\begin{array}{cc}
\boldsymbol{\beta}_{\mathrm{ij}}^{\mathrm{l}}, \quad \mathbf{X}<\mathbf{X}_{\mathrm{gel}} \quad \text { и } \quad \mathbf{T} \geq \mathbf{T}_{\mathbf{g}}(\mathbf{X}) \\
\boldsymbol{\beta}_{\mathrm{ij}}^{\mathrm{r}}, \quad \mathbf{X} \geq \mathbf{X}_{\mathrm{gel}} \quad \text { и } \quad \mathbf{T} \geq \mathbf{T}_{\mathbf{g}}(\mathbf{X}) \\
\\
\boldsymbol{\beta}_{\mathrm{ij}}^{\mathrm{g}}, \quad \mathbf{T}<\mathbf{T}_{\mathbf{g}}(\mathbf{X}) .
\end{array}\right.
$$

where $\beta_{i j}^{l}, \beta_{i j}^{r}$, and $\beta_{i j}^{g}$ are the linear coefficients of chemical shrinkage in the liquid, rubbery, and glassy states, respectively.

The dependence of the glass transition temperature $\boldsymbol{T}_{\mathrm{g}}$ on the degree of cure $\alpha$ was defined using the Di Benedetto equation [32]:

$\frac{T_{\mathrm{g}}-\boldsymbol{T}_{\mathrm{g} 0}}{T_{\mathrm{g} \infty}-T_{\mathrm{g} 0}}=\frac{\lambda X}{1-(1-\lambda) X}$,

where $\boldsymbol{T}_{\mathrm{g} \boldsymbol{0}}$ and $\boldsymbol{T}_{\mathrm{g} \infty}$ are the glass transition temperatures of the uncured $(\boldsymbol{X}=0)$, respectively, fully cured system $(\boldsymbol{X}=1)$; and $\boldsymbol{\lambda}$ is a material constant.

In [14, 22], the main constitutive relations are given, which serve to describe the curing process of a composite material with a thermosetting matrix. These models describe the material in rubbery and glassy states.

In this paper, several defining relations of the elasticity model in simulating the process-induced stresses are used. When the modules are piecewise constant and are written as [22]

$\sigma_{i j}=\left\{\begin{array}{c}C_{i j k l}^{R} \varepsilon_{k l}^{M}, T \geq T_{\mathbf{g}}(X), \\ C_{i j k l}{ }^{G} \varepsilon_{k l}^{M}, T<T_{\mathbf{g}}(X),\end{array}\right.$

where $\boldsymbol{C}_{i j k l}^{R}$ and $\boldsymbol{C}_{i j k l}^{G}$ components of the elastic module tensors in the rubbery and glassy states, respectively.

And when elastic module tensors change calculated by the Cure Hardening Instantaneous Linear Elastic (CHILE) model $[14,33,34]$

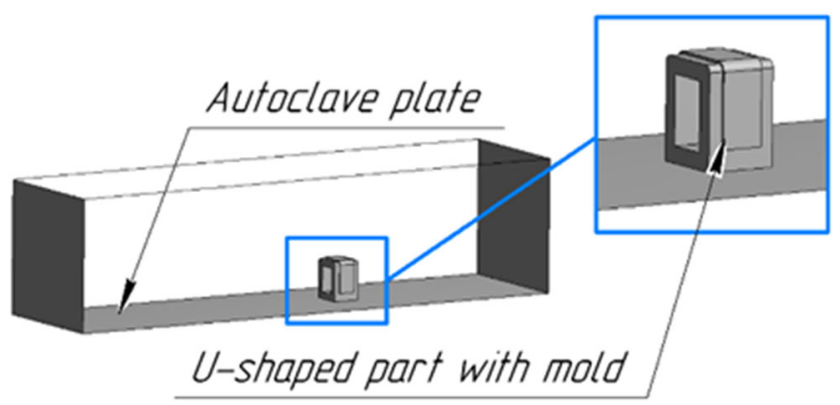

Fig. 3 Autoclave scheme

$$
\sigma_{i j}=\left\{\begin{array}{cc}
C_{i j k l}^{R}, & T \geq T_{g}(X), \\
C_{i j k l}^{R}+\frac{T^{*}-T_{C 1}}{T_{C 2}-T_{C 1}}\left(C_{i j k l}^{G}-C_{i j k l}^{R}\right), & T_{C 1} \leq T^{*} \leq T_{C 2}, \\
C_{i j k l}^{G}, & T<T_{g}(X)
\end{array}\right.
$$

where $\boldsymbol{T}^{*}=\boldsymbol{T}_{g}(\boldsymbol{X})-\boldsymbol{T}$ and $\boldsymbol{T}_{C 1}$ and $\boldsymbol{T}_{C 2}$ are material parameters.

To be able to simulate using the finite element method, the direct Euler scheme is used [22]

$\varepsilon_{k l}^{E}(t+\Delta t)=\varepsilon_{k l}^{E}(t)+\Delta \varepsilon_{k l}^{E}$,

where

$\Delta \varepsilon_{k l}^{E}=\Delta \varepsilon_{k l}^{T}+\Delta \varepsilon_{k l}^{C}$,

$\Delta \varepsilon_{k l}^{T}=\alpha_{k l} \Delta T$

$\Delta \varepsilon_{k l}^{C}=\beta_{k l} \Delta X$

where $\Delta \boldsymbol{T}_{\text {и }} \boldsymbol{\Delta} \boldsymbol{X}$ are are the temperature, respectively, degree of cure increment over the time step. According to [22], the coefficients for linear shrinkage in the liquid state $\boldsymbol{\alpha}_{\boldsymbol{k} \boldsymbol{l}}$ и $\boldsymbol{\beta}_{\boldsymbol{k} \boldsymbol{l}}$ are taken as zero.

\section{Finite element model}

\subsection{FE Implementation}

A nonstationary simulation of heat transfer process according to a given curing temperature cycle in an implicit ABAQUS Standard solver is carried out with taking into account geometric nonlinearity.

Relationships for thermal and mechanical behavior are implemented with using subroutines USDFLD, HETVAL, UEXPAN, and UMAT, written in the FORTRAN programming language.

With using USDFLD, the dependence of thermal conductivity and specific heat on temperature and cure degree is determined.

The user subroutine HETVAL defines the internal heat generation of the material as a result of the exothermic reaction as a function of the cure rate. The reaction rate expression is a differential equation and is solved by an improved Euler method.

Table 3 Description of the meshes with different qualities: number of elements, $Y+$ over the U-shaped part top side

\begin{tabular}{llll}
\hline Model & Coarse & Medium & Fine \\
\hline No. of elements & $1,242,300$ & 248,600 & $4,971,000$ \\
$Y^{+}$ & 7.6 & 5.2 & 4.5 \\
\hline
\end{tabular}


Fig. 4 CFD model and boundary conditions

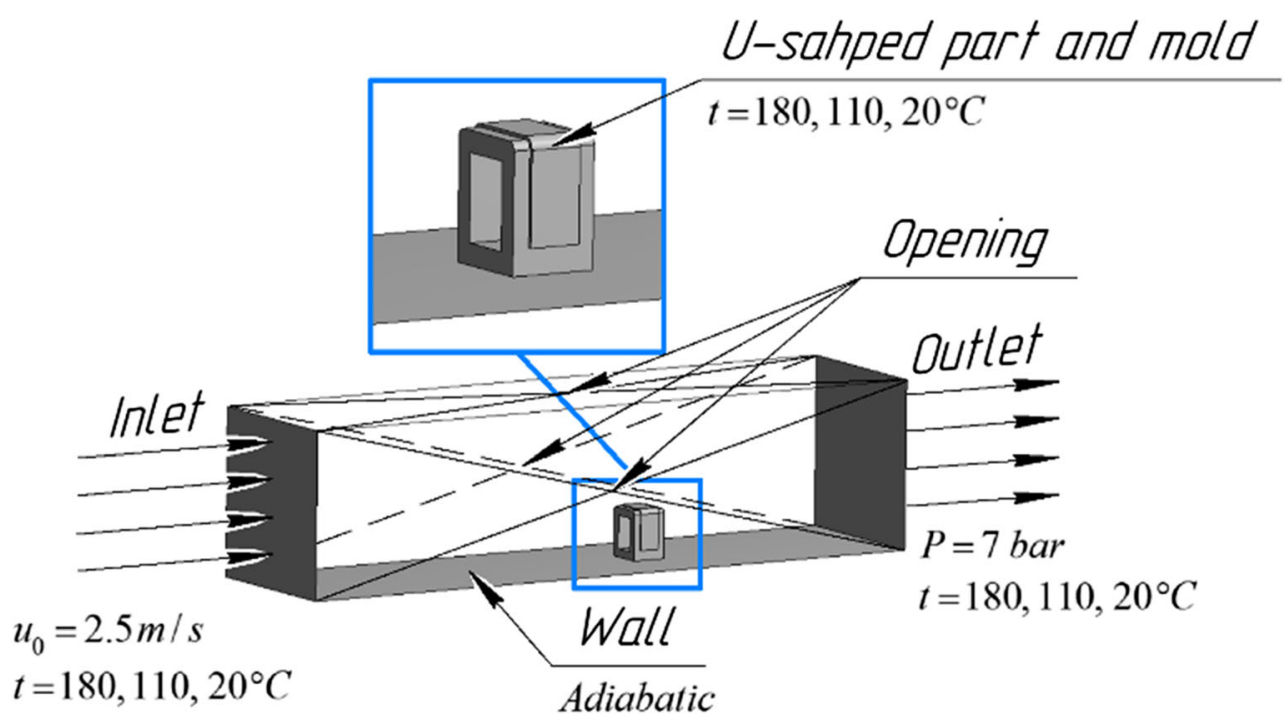

With using UEXPAN, the orthotropic thermal expansion and chemical shrinkage coefficients are determined depending on current cure degree and temperature.

The UMAT was used to set the elastic properties of the material for the rubbery and glassy states of the matrix, and also to calculate the mechanical stresses.

Thus, the cure degree, the increment in thermal and shrinkage strains, and the update of the elasticity tensor are performed at each integration point at each time step, which allows taking into account the history of the process.

\subsection{U-shaped sample FE model}

Resin parameters for Kamal-Sourour model (3) are presented in Table 1 [35].

In the FE model, each ply represents a solid part. Each ply was represented by one solid element in thickness. The element type C3D8T is used to simulate a coupled thermomechanical problem. The laminate consists of 8 plies and has the lay-up $[0 / 90 / 45 /-45] \mathrm{s}$. The ply properties are presented in Table 2 [15].

The properties of the mold material were set as for aluminum.

At each of the three analysis steps («Initial», «Curing» «Springback»), specific boundary conditions are set (Fig. 1).

At the «Initial» step, thermal and mechanical contact, temperature $20^{\circ} \mathrm{C}$, and constraints on the bottom surface of the mold are set.

In the «Curing» step, the heat transfer coefficient on the free surface of the part and mold equal to $45 \mathrm{~W} /\left(\mathrm{m}^{2} \cdot \mathrm{K}^{-1}\right)$ and the cure temperature cycle are set. On the outer surface of the part a pressure of $0.7 \mathrm{MPa}$ is set.

The «Springback» step simulates the part demolding. The following boundary conditions are deactivated: heat transfer coefficient and external pressure; mechanical and thermal contact between part and mold. For the part, boundary conditions are set that allow it free to move.

The interaction between the part and the mold was defined using «Surface-to-surface contact».

In the «Normal behavior» mechanical contact property, by default, a «Hard» contact pressure-overclosure relationship is used for surface-based contact. When surfaces are in contact, any contact pressure can be transmitted between them. The surfaces separate if the contact pressure reduces to zero.

In the «Tangential behavion» mechanical contact property, Coulomb friction is used. The Coulomb friction model defines

Table 4 Description of the boundary conditions

\begin{tabular}{llll}
\hline Boundary condition & Symbol & Dimension & Value \\
\hline Inlet & $T_{\infty}$ & $(\mathrm{K})$ & 453.15 \\
Temperature & & & 383.15 \\
& $u_{0}$ & $\left(\mathrm{~m} \cdot \mathrm{s}^{-1}\right)$ & 293.15 \\
Velocity & & & 2.5 \\
Outlet & $P$ & $(\mathrm{~Pa})$ & \\
Pressure & $T_{\infty}$ & $(\mathrm{K})$ & 700,000 \\
Temperature & & & 453.15 \\
& & & 383.15 \\
& - & & 293.15 \\
Autoclave plane & $T_{\infty}$ & $(K)$ & Adiabatic \\
U-shaped part and mold walls & & 453.15 \\
Temperature & & - & 383.15 \\
& & & 293.15 \\
& & & Opening \\
\hline
\end{tabular}


Fig. 5 The maximum temperature of the part and mold for constant air temperature $\left(110^{\circ} \mathrm{C}\right)$ in the model without thermal contact
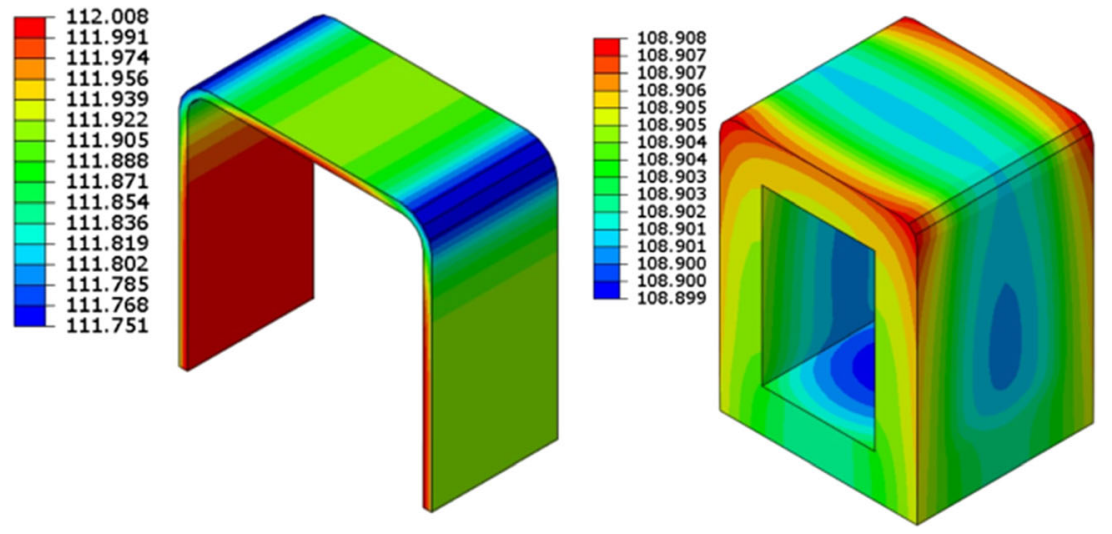

critical shear stress $\left(\tau_{\text {crit }}\right)$ at which sliding of the surfaces starts as a fraction of the contact pressure $(p)$ between the surfaces $\left(\tau_{\text {crit }}=\mu p\right)$. The fraction $(\mu)$ is known as the coefficient of friction and is set to 0.25 .

Thermal contact was set using the conductance and clearance parameters.

The model has been validated based on research $[11,12]$.

\subsection{Stiffened composite curved panel FE model}

The laminate consists of 8 plies and has the lay-up [+45/-45/ 90/0]s for panel and each stringers. The laminated composite was modeled similarly to the U-shaped part as described in Sect. 3.2. The boundary conditions are shown in Fig. 2.

\section{Computational fluid dynamics model}

The method for HTC determination HTC is the same for LCM and autoclave molding methods. Depending on the molding method, the geometrical dimensions of the oven/autoclave, temperature and boundary conditions will differ. For a reliable description of the processes in the autoclave, it is necessary to simulate the complete geometry, as well as the unsteady process of heating the air flow that blows the part and the mold.
The need to model the complete geometry is due to the fact that the flow pattern inside the autoclave can be quite complex with the formation of eddies. The unsteadiness of the process is caused by a change in temperature according to the curing cycle. Also, as a result of temperature changes, the air thermos-physical properties change, and, accordingly, the HTC.

Curing of a thermoset composite material in an autoclave is a nonstationary process with a given temperature regime. In order to determine the boundary and initial conditions for setting, stationary CFD-modeling tasks used the results of the preliminary coupled temperature-displacement calculation in the commercial software package ABAQUS CAE.

A stationary model of the fluid dynamics and the heat transfer in autoclave has been set up in the commercial software package ANSYS CFX discretizing the incompressible Reynolds Averaged Navier-Stokes equations and total energy transport equation. The $\mathrm{k}-\varepsilon$ turbulence model has been chosen as one of the most common models for technical applications.

In order to reduce the scale of the case and also CPU time, some parts of the autoclave in which the air flow is not of interest are excluded from consideration (Fig. 3).

The discretization has been done manually using an unstructured mesh approach. Three different variants of discretization with different element sizes were used in order
Fig. 6 The maximum temperature of the part and mold for constant air temperature $\left(180^{\circ}\right.$ C) in the model without thermal contact
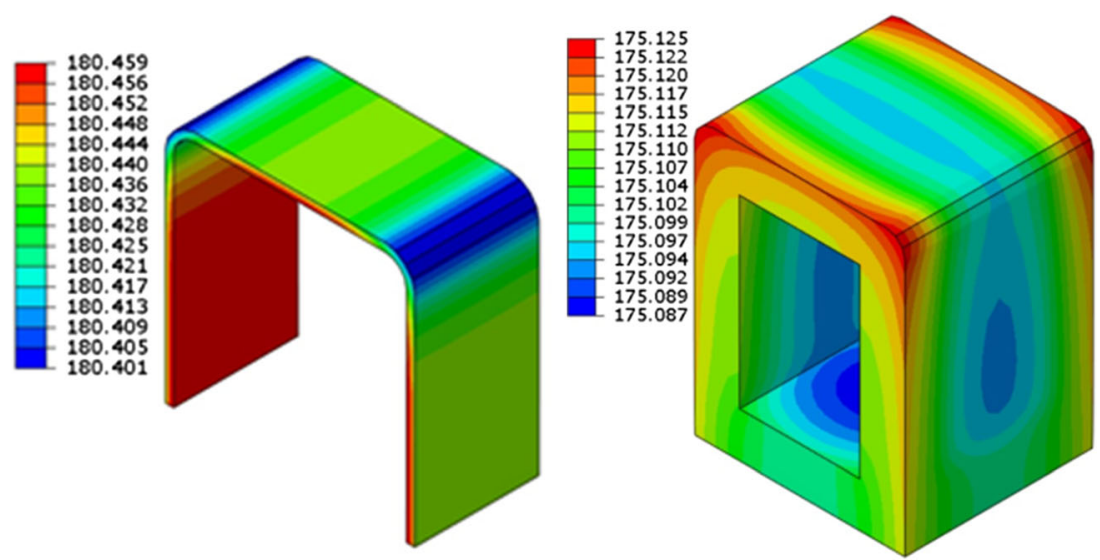
Fig. 7 The maximum temperature of the part and mold for constant air temperature $\left(180^{\circ} \mathrm{C}\right)$ in the model with thermal contact
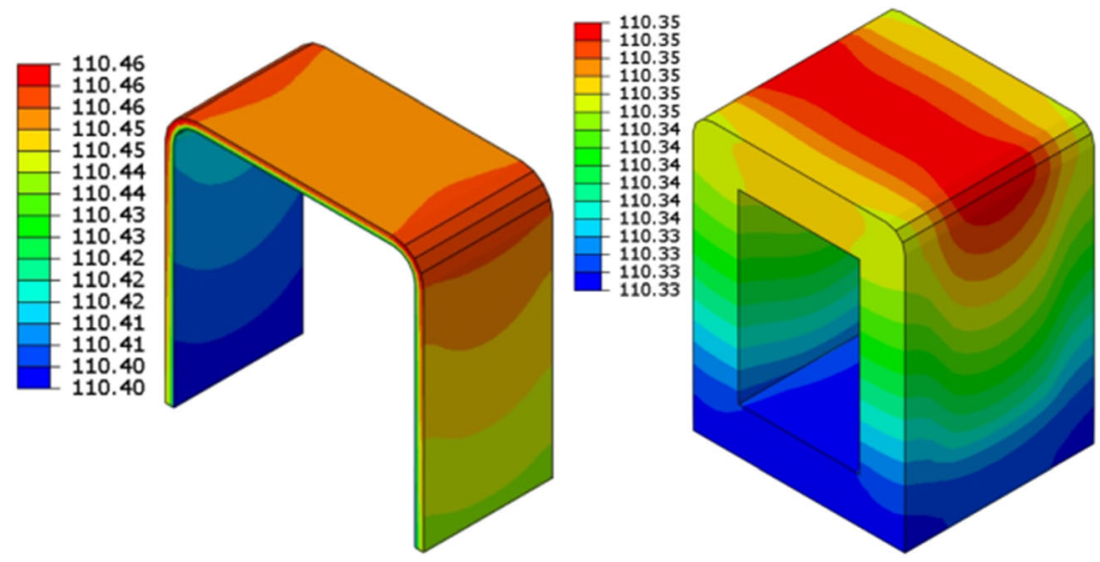

to check the convergence of the results of CFD-simulation. The description of the meshes is given in Table 3. All meshes feature a high mesh density at the plate of the autoclave and the U-shaped part to provide an accurate representation of the boundary layer.

Model and boundary conditions are shown in Fig. 4.

Autoclave panel is considered to be adiabatic; boundary conditions on the sidewalls are defined as «opening». The inlet velocity was assumed to be constant over the inlet plane. The direction of the velocity vector was assumed to be perpendicular to the inlet plane. The description of boundary conditions is given in Table 4.

Boundary conditions are based on the results obtained in [28].

\section{Results}

\subsection{U-shaped part with constant heat transfer coefficient}

First, simulation was carried out with a constant HTC (45 $\left.\mathrm{W} /\left(\mathrm{m}^{-2} \mathrm{~K}^{-1}\right)\right)$ on the surface of the part and mold.
Figures 5 and 6 show the temperature distribution of the part and mold without thermal contact at the moment of the greatest local overheating of the part for constant air temperature of the autoclave $-110^{\circ} \mathrm{C}$ and $180^{\circ} \mathrm{C}$, respectively. This temperature rise above the cycle temperature is due to the exothermic heat generated by curing.

Figure 7 shows the temperature distribution at the moment of the greatest local overheating of the part, taking into account the thermal contact between the part and the mold. Compared to the model without thermal contact, it can be seen, that the temperature rise in this model was $0.46^{\circ} \mathrm{C}$ more, than the cycle temperature. This is due to the fact that the heat supplied to the part and released as a result of the cure reaction is partially transferred to the mold.

Figure 8 shows the distribution of the degree of cure after gelation of the resin. In the model with thermal contact at the same time, the degree of cure is lower.

Analysis of the results in Figs. 5-8 shows that, without taking into account thermal contact, the most heated zones in the part arise closer to the mold. In the same zones, the degree of cure is higher. Taking into account the thermal contact, the most heated zones and the higher the degree of cure arise at the radius of the part on the outer surfaces.
Fig. 8 The degree of cure after gelation of the resin in the model without thermal contact (left) and with thermal contact (right) at the time $7240 \mathrm{~s}$
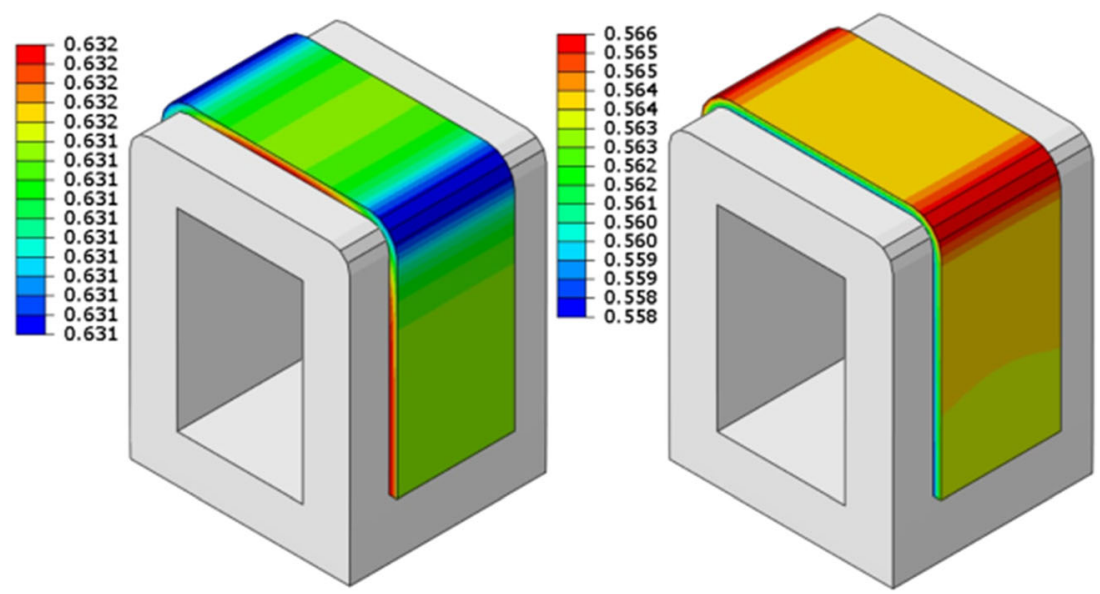
Fig. 9 U-shaped part temperature and curing rate with taking into account thermal contact

Fig. 10 U-shaped part heat flux during cure process with thermal contact
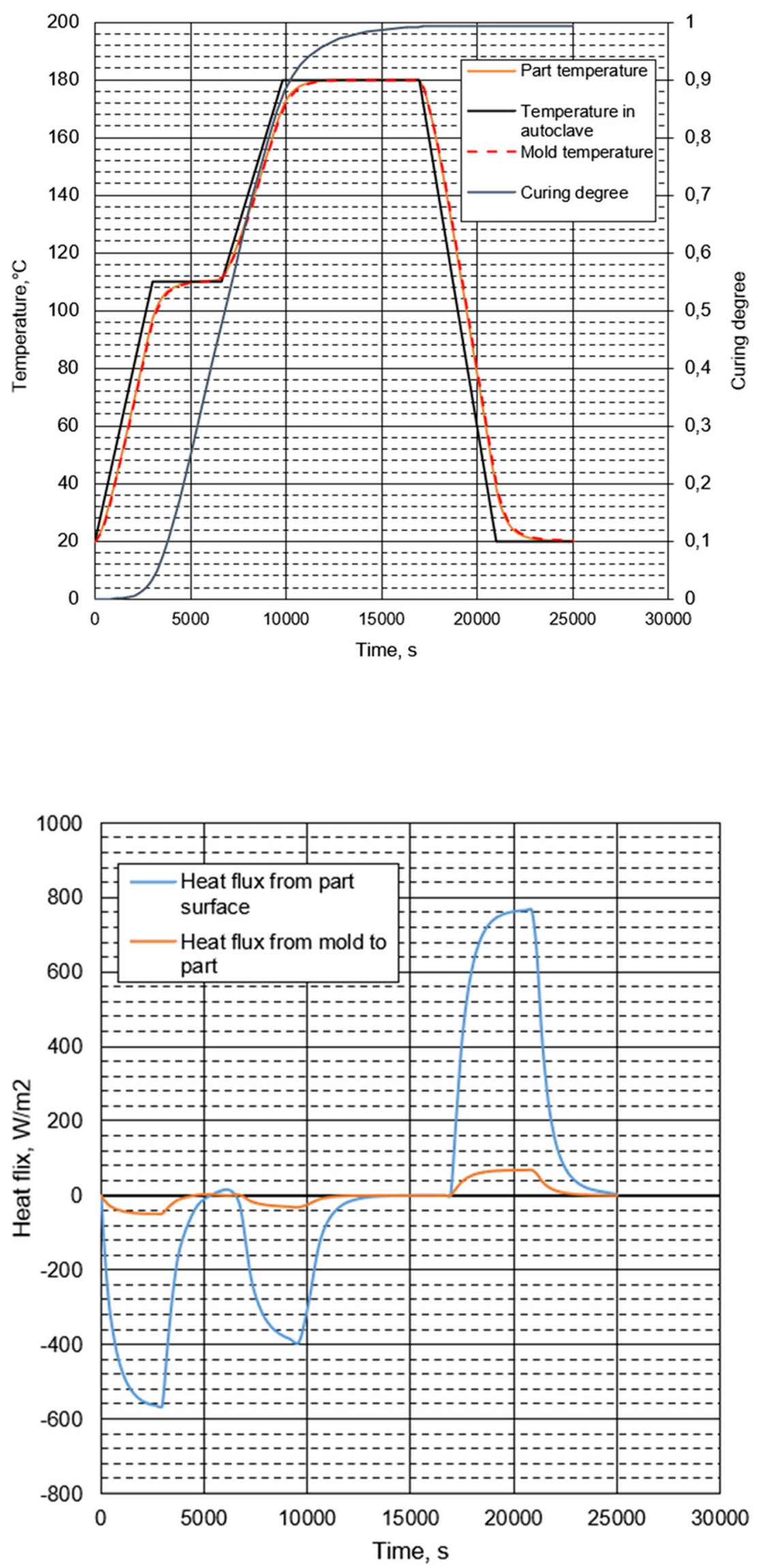
Fig. 11 Effect of thermal contact on U-shaped part temperature (2 $\mathrm{mm}$ )

Fig. 12 Effect of thermal contact on U-shaped part temperature (6 $\mathrm{mm}$ )
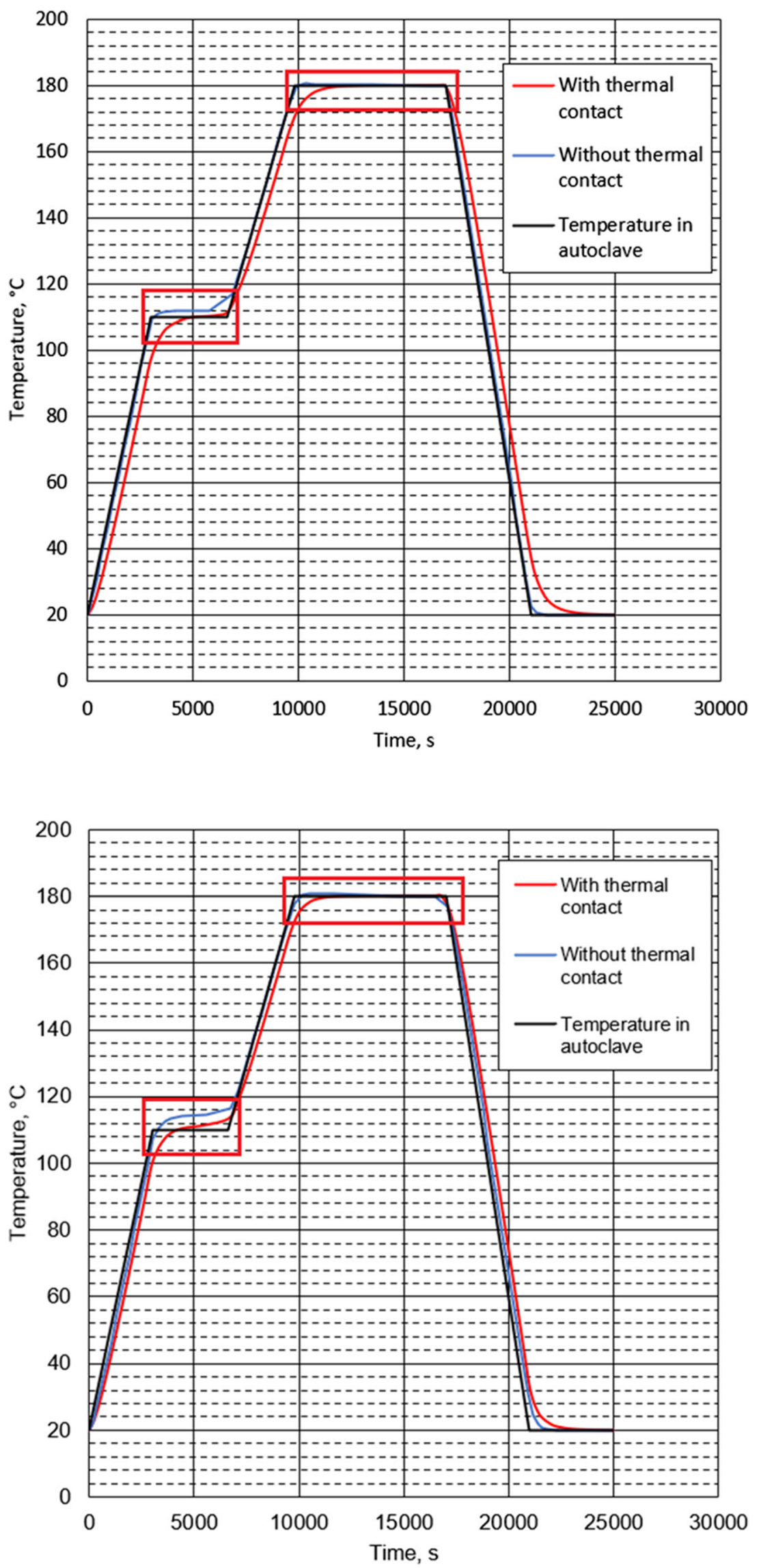
Fig. 13 Effect WHTC on Ushaped part temperature $(6 \mathrm{~mm})$

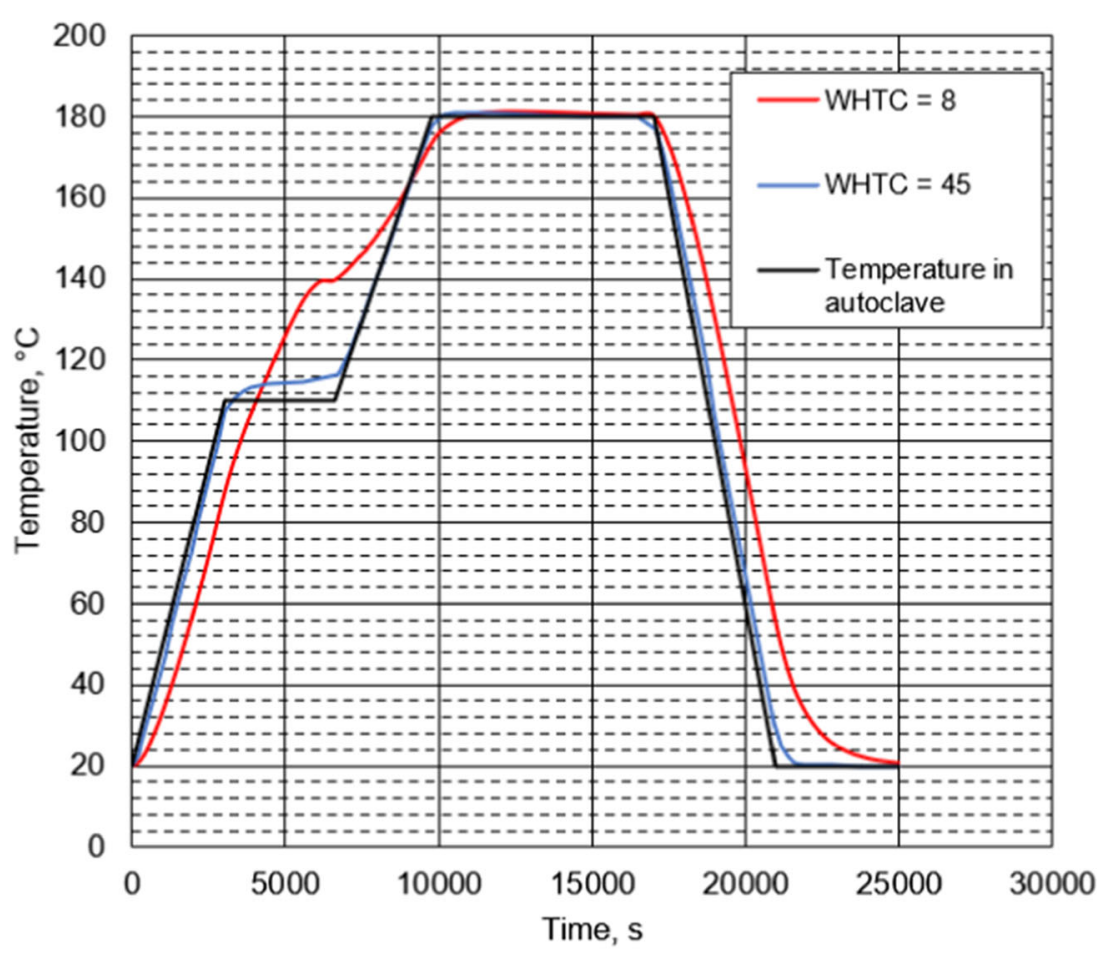

Figure 9 shows the change in cure degree, temperature of U-shaped part, and change of temperature in autoclave over time with thermal and mechanical contact between U-shaped part and mold.

The graphs show that the temperature of the part differs $\left(\sim 20^{\circ} \mathrm{C}\right)$ from the temperature of the autoclave cycle at the initial and final stages. This effect arises due to taking into account the thermal contact between U-shaped part and mold which allows heat exchange through the contact surface. On the initial stage and on the final stage of the thermal cycle mold and U-shaped part, temperature values practically coincide, but heat transfer still occurs between them.

It can be seen on Fig. 10, where negative heat flux-is a heat flux into the body, positive heat flux-is a heat flux from the body.

Figure 11 shows a temperature graph for a 2-mm-thick part. With thermal contact, temperature differs little from
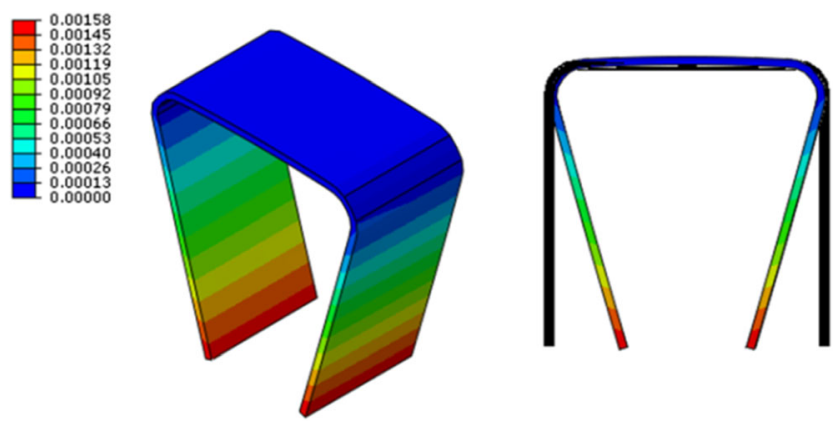

Fig. 14 Demolding and shape distortion (m) temperature of cycle in autoclave at the regions with constant temperature framed on Fig. 11. Without thermal contact between mold and U-shaped part, temperature rises become more noticeable $\left(\sim 2^{\circ} \mathrm{C}\right)$. In the same time with thermal contact temperature, rises are less $\left(\sim 0.5^{\circ} \mathrm{C}\right)$. The increase over the autoclave temperature in these areas is explained by the occurrence of exothermic chemical reactions in the part.

The thickness of the part affects the amount of temperature rise in framed areas: with increasing thickness of the part the maximum temperature gets higher. It can be seen by comparing Figs. 11 and 12.
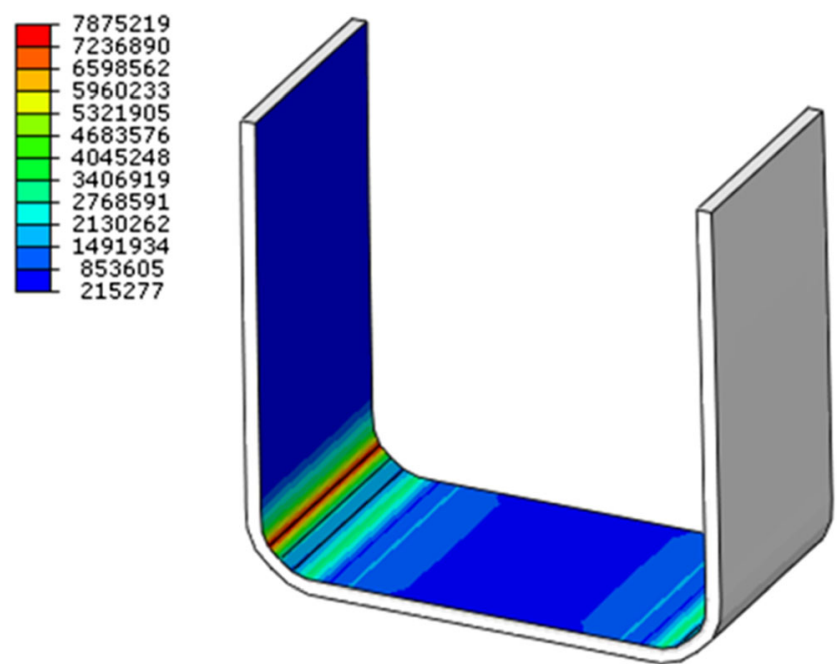

Fig. 15 Maximum contact pressure $(\mathrm{Pa})$ 
Fig. 16 U-shaped sample temperature and surface heat flux during cure process

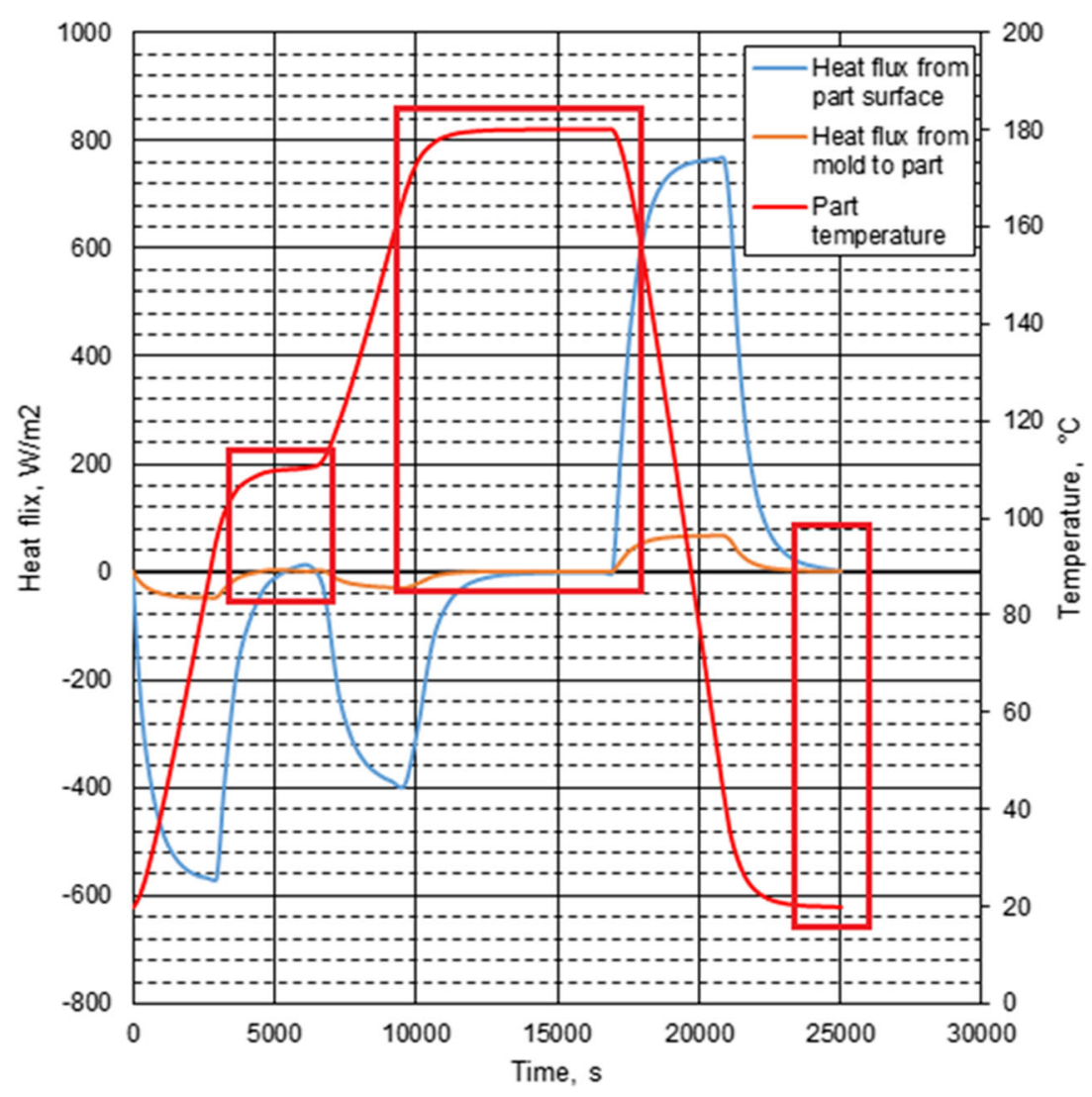

As shown in Fig. 13 with an increase in the HTC, the value of the rise of part temperature in the thermal cycle sections with a constant temperature decreases: with $\mathrm{HTC} \sim 8 \mathrm{~W} /\left(\mathrm{m}^{-2}\right.$ $\mathrm{K}^{-1}$ ) part temperature rise over autoclave temperature cycle is $\sim 30^{\circ} \mathrm{C}$; with $\mathrm{HTC} \sim 45 \mathrm{~W} /\left(\mathrm{m}^{-2} \mathrm{~K}^{-1}\right)$ part temperature rise over autoclave temperature cycle is $\sim 5^{\circ} \mathrm{C}$. This effect can be explained by the fact that at the moment of intense exothermic heat generation the temperature of the part becomes higher than the air temperature in the autoclave, and with a higher HTC, the air flow cools the part better.

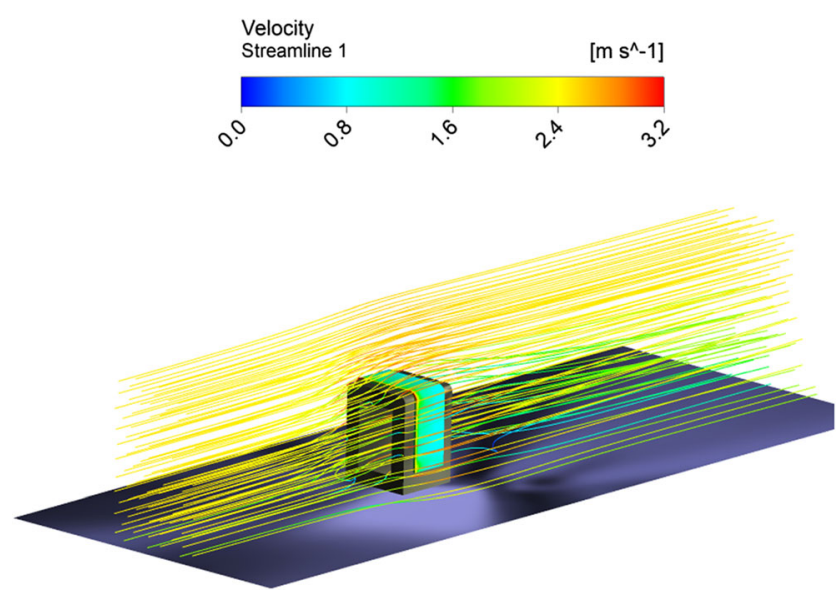

Fig. 17 Stationary flow field
Figure 14 shows the final shape of the part and the change from the nominal dimensions after demolding at the «Springback» step.

Figure 15 shows the maximum contact pressures acting on the part from the mold side during the curing process.

\subsection{U-shaped part with heat transfer coefficient from CFD simulation}

The above results were obtained under the condition of constant value of the heat transfer coefficient on the surface of the part.

To simplify the formulation of the CFD calculation, the cycle area with stationary value of temperature and zero heat flux is chosen. These sections are highlighted in Fig. 16 with a red frame.

In accordance with the above methodology and the CFD model, an analysis of the flow around a part and mold in an autoclave was carried out (Fig. 17).

According to the simulation results shown in Fig. 18, it can be seen that the HTC depends little on the surface temperature of the part. The values of the HTC averaged over the part surface are shown in Table 5.

The validation of the CFD simulation of the HTC in an autoclave was carried out according to the results given in [28]. 
Fig. 18 Wall heat transfer coefficient on U-shaped part surface

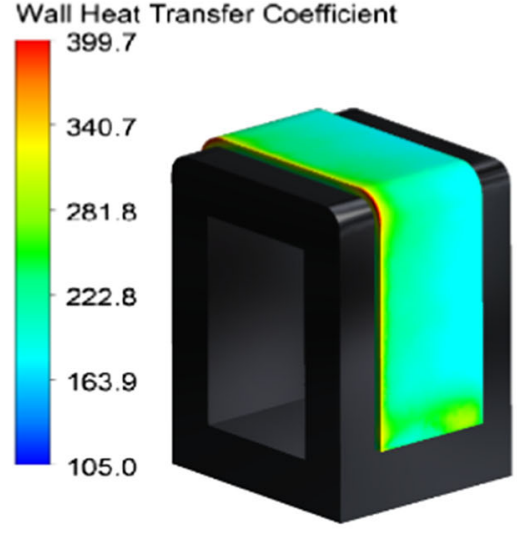

$180^{\circ} \mathrm{C}$

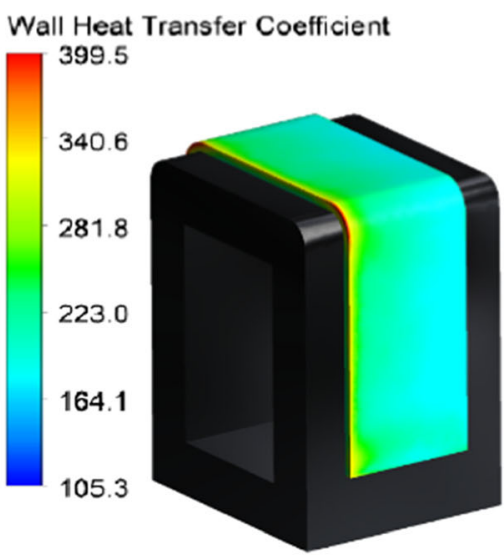

$110^{\circ} \mathrm{C}$

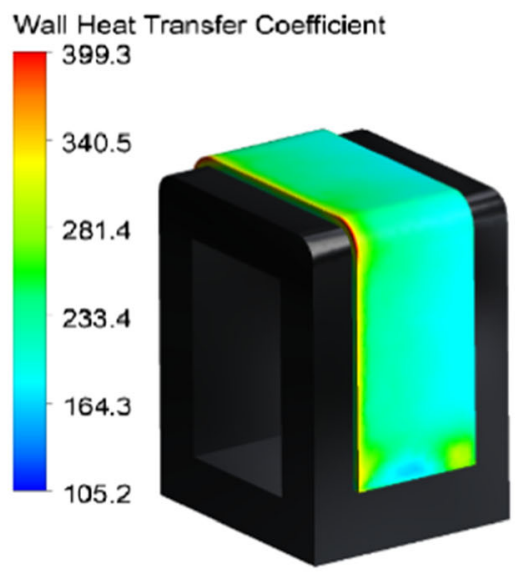

$20^{\circ}$

Figure 19 shows the temperature distribution fields on the part surface at different times, corresponding to the thermal cycle areas with a constant air flow temperature $(110,180$, $20^{\circ} \mathrm{C}$ ). It can be seen from the figures that the temperature distribution over the surface of the part is nonuniform, but the difference between the maximum and minimum surface temperatures is in the range from 0.01 to $0.3^{\circ} \mathrm{C}$. Figure 19 shows that for a given part, the influence of nonuniformity of the HTC does not significantly affect the temperature field distribution. The same conclusion is valid for the cure rate and degree of cure. Figure 20 shows that the degree of cure and the cure rate for cases of uneven and uniform distribution of the HTC over the part surface practically coincide.

However, for larger parts with greater thickness, the effect of nonuniformity of the HTC over its surface on the curing rate and the cure degree can be significant.

\subsection{Stiffened composite curved panel}

Figure 21 shows the results of a stringer panel simulation in according to described methodology with constant typical
HTC without account into mold. Maximum displacement from nominal geometry due to process-induced residual strains is predicted.

\section{Conclusions}

A new technique has been developed that can be used by engineers to assess residual technological deformations. The technique makes it possible to estimate process-induced residual strains with mold, depending on the requirements for modeling accuracy and available computing resources.

Table 5 Averaged wall heat transfer coefficient (WHTC)

\begin{tabular}{ll}
\hline Temperature $\left({ }^{\circ} \mathrm{C}\right)$ & WHTC $\left(\mathrm{W} /\left(\mathrm{m}^{2} \mathrm{~K}^{-1}\right)\right)$ \\
\hline 180 & 219.5 \\
110 & 213.7 \\
20 & 210.4 \\
\hline
\end{tabular}


Fig. 19 Temperature field on part and mold surfaces with imported WHTC from CFD simulation
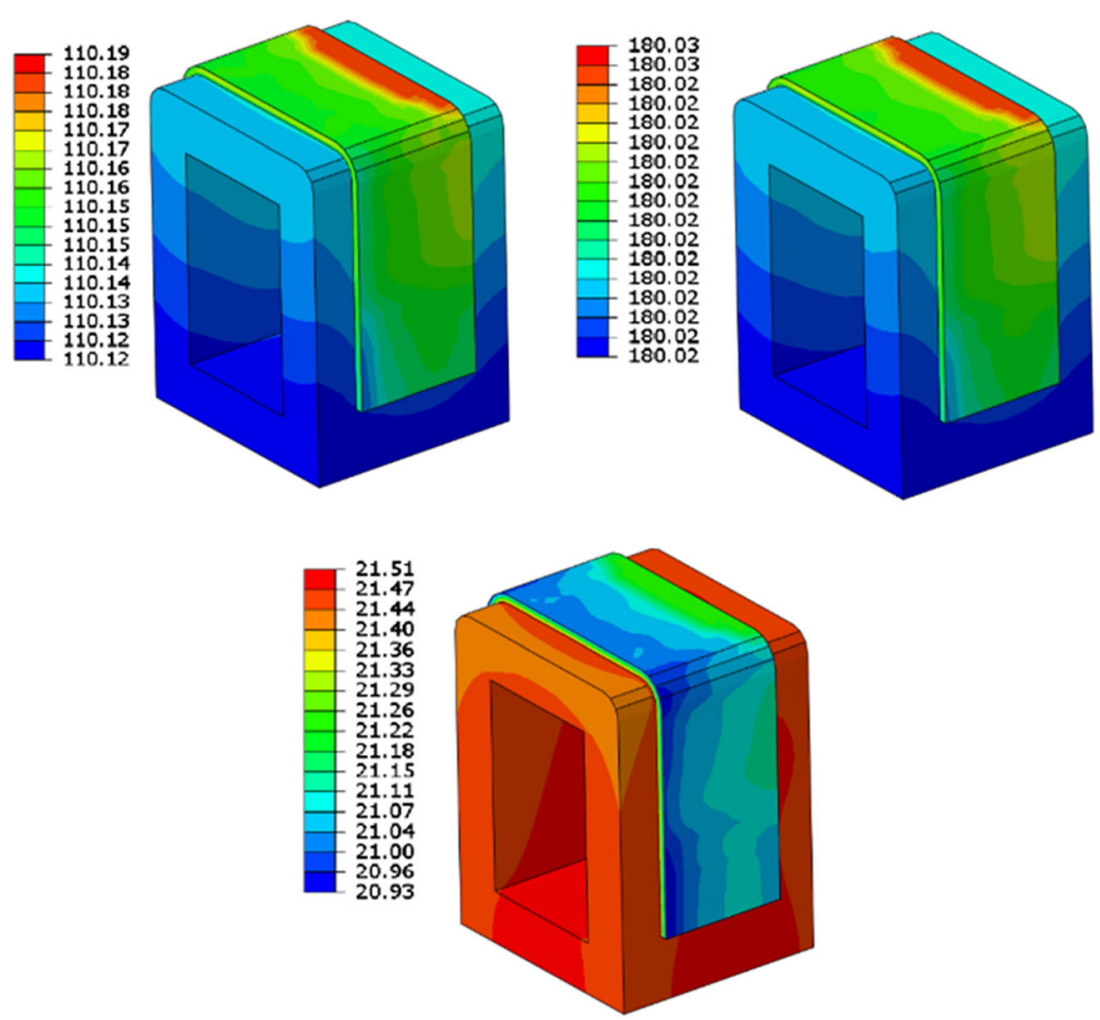

The presence of the mold significantly affects the simulation results. Mold through thermal expansion and mechanical contact affects the final shape of the part. Also, the mold has a significant impact on the modeling of heat conduction process between the part and the mold due to thermal contact.
The accuracy of solving the heat problem depends on the specified HTC on the surface of the part and mold. When specifying the typical HTC, using the literature data, one may encounter a large scatter of this value. The HTC itself on the surface of the part in the oven/autoclave will depend on the part geometry, temperature cycle, air properties, and boundary conditions.
Fig. 20 Curing degree and rate with uniform and uneven WHTC on the part surface

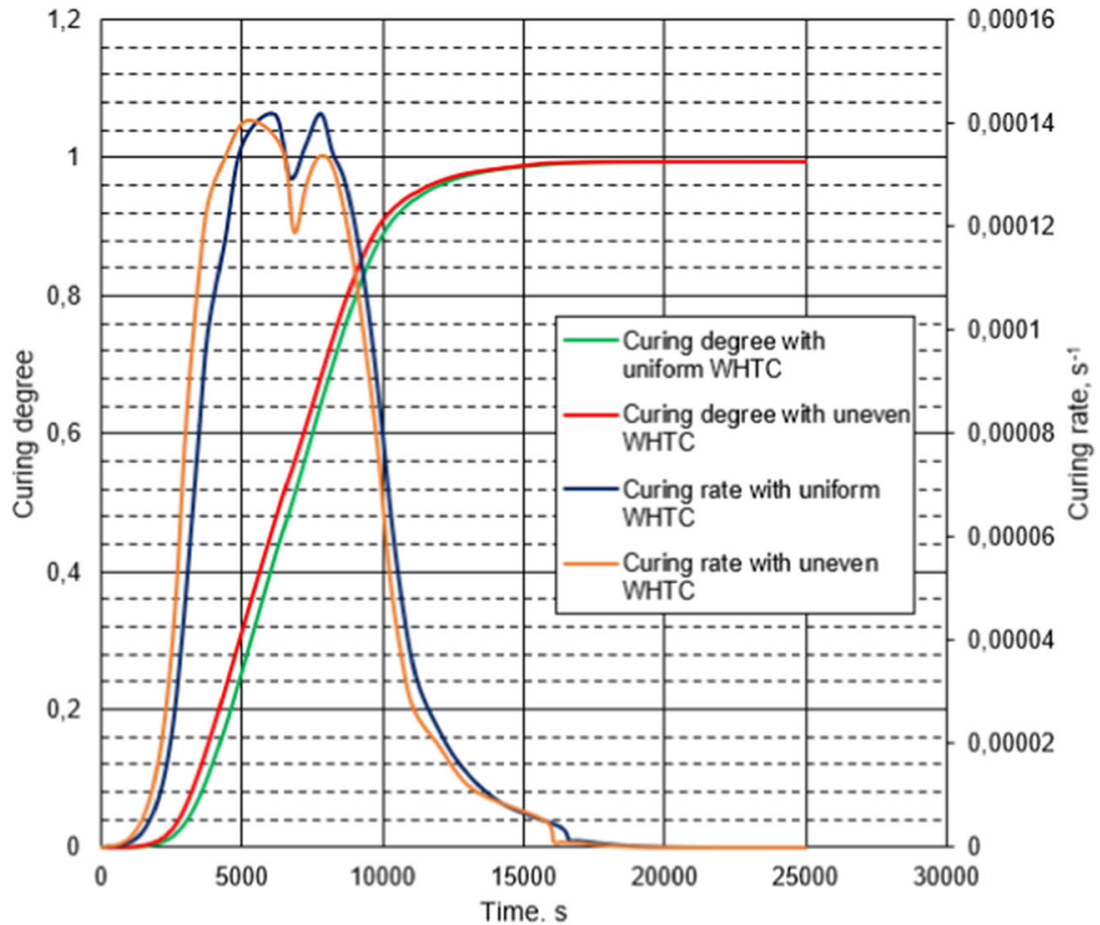




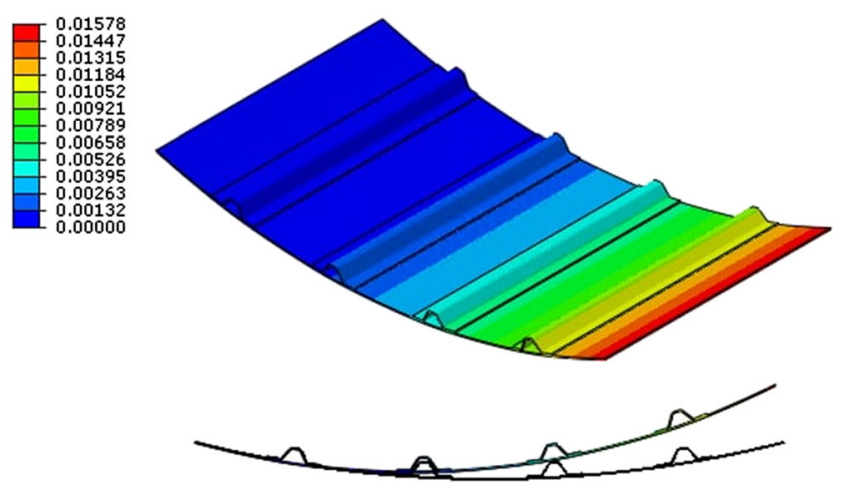

Fig. 21 Maximum displacement due to process-induced residual strains (m)

Therefore, it is important for parts requiring increased geometric accuracy to carry out CFD simulation to refine HTC.

In a future study, it is planned to validate the models based on the experiment results and to clarify recommendations for the method application. The influence of the size and type of time step (fixed/automatic) on the results should be investigated.

Author contribution Mikhail Kiauka: Introduction; constitutive material model, finite element model, and preparation of conclusions; general concept and original draft preparation; analysis of simulation results; review; and writing and editing. Mikhail Kasatkin: Computational fluid dynamics model preparation; post-processing of results; and analysis of the effect of thermal contact, heat transfer coefficients, and part thickness on the temperature field and cure degree. Iuliia Tcygantceva: thermal and mechanical contact research and post-processing of simulation results. Nikolai Efimov-Soini: Introduction preparation, writing, review, and editing. Alexey Borovkov: Preparation of conclusions and editing.

Funding This research is funded by the Ministry of Science and Higher Education of the Russian Federation as a part of the World-Class Research Center Program: Advanced Digital Technologies (contract No. 075-15-2020-934 dated 17 November 2020).

Availability of data and material Not applicable.

Code availability Not applicable.

\section{Declarations}

Ethical approval Not applicable.

Consent to participate Not applicable.

Consent to publish Not applicable.

Competing interests The authors declare no competing interests.

Open Access This article is licensed under a Creative Commons Attribution 4.0 International License, which permits use, sharing, adaptation, distribution and reproduction in any medium or format, as long as you give appropriate credit to the original author(s) and the source, provide a link to the Creative Commons licence, and indicate if changes were made. The images or other third party material in this article are included in the article 's Creative Commons licence, unless indicated otherwise in a credit line to the material. If material is not included in the article 's
Creative Commons licence and your intended use is not permitted by statutory regulation or exceeds the permitted use, you will need to obtain permission directly from the copyright holder. To view a copy of this licence, visit http://creativecommons.org/licenses/by/4.0/.

\section{References}

1. Duffour $\mathrm{C}$ et al (2017) Coupled fabric deformation and infusion process simulation. Prog Phys Geogr 14(7):450. https://doi.org/ 10.1177/0309133309346882

2. Khan MA, Mabrouki T, Vidal-Sallé E, Boisse P (2010) Numerical and experimental analyses of woven composite reinforcement forming using a hypoelastic behaviour. Application to the double dome benchmark. J Mater Process Technol 210(2):378-388. https://doi.org/10.1016/j.jmatprotec.2009.09.027

3. Pierce RS, Falzon BG (2017) Simulating resin infusion through textile reinforcement materials for the manufacture of complex composite structures. Engineering 3(5):596-607. https://doi.org/ 10.1016/J.ENG.2017.04.006

4. Radford DW, Rennick TS (2000) Separating sources of manufacturing distortion in laminated composites. $J$ Reinf Plast Compos 19(8):621-641.https://doi.org/10.1177/ 073168440001900802

5. Fernlund G, Poursartip A, Twigg G, Albert C (2003) Residual stress, spring-in and warpage in autoclaved composite parts. 14th Int Conf Compos Mater, no. Figure 1 Available: http://www. convergent.ca/Objects/Publications/2003-ICCM14-Res_Stress_ Spring-In_Warp.pdf

6. Albert CI (2001) Spring-In of angled thermoset composite laminates. Master Thesis

7. Pochiraju KV (2002) Multi-physics modeling and simulation of process-induced stresses in polymer matrix composites. 298(19)

8. Kiauka M, Pudeleva O, Sergeev V, Tamm A, Borovkov A (2020) An approach to modelling the manufacturing process of thermoset composite reinforced with 3D woven. Proc 6th World Congr Mech Chem Mater Eng:1-7. https://doi.org/10.11159/htff20.181

9. M Kiauka, O Pudeleva, A Tamm, and A Borovkov, "The curing simulation and prediction of shape distortion of thermoset composite reinforced with $3 \mathrm{D}$ woven the curing simulation and prediction of shape distortion of thermoset composite reinforced with 3d woven," 2020, doi: https://doi.org/10.1088/1757-899X/986/1/012041.

10. Svanberg JM, Holmberg JA (2004) Prediction of shape distortions. Part II. Experimental validation and analysis of boundary conditions. Compos Part A Appl Sci Manuf 35(6):723-734. https://doi. org/10.1016/j.compositesa.2004.02.006

11. J M Svanberg, "Predictions of manufacturing induced shape distortions: high performance thermoset composites," p. 131, 2002, [Online]. Available: http://epubl.luth.se/1402-1544/2002/40/ index-en.html

12. Svanberg JM (2002) Shape distortion of non-isothermally cured composite angle bracket. Plast Rubber Compos 31(9):398-404. https://doi.org/10.1179/146580102225006422

13. Barat S, Dores E, Del Rosa Y (2014) Experimental and numerical study of spring-in angle in corner shaped composite parts. A thesis Submitt to Grad Sch Nat Appl Sci Middle East Tech Univ

14. Kozlov MV, Sheshenin SV, Makarenko IV, Belov DA (2016) Modeling the influence of tooling on the final shape of polymer composite parts. Comput Contin Mech 9(2):145-161. https://doi. org/10.7242/1999-6691/2016.9.2.13

15. Kozlov MV, Sheshenin SV, Babkin AV, Kepman AV, Kudrin AM (2016) Modeling of forming of composites based on thermosetting 
matrices. Vestnik Voronezhskogo gosudarstvennogo tekhnicheskogo universiteta 3:11-17

16. Tavakol B (2011) Prediction of residual stresses and distortion of carbon fibre/epoxy composites due to curing process. Thesis A Thesis by Behrouz Tavakol Bachelor Sci Amirkabir Univ Technol 2007 (72) Available: https://soar.wichita.edu/handle/10057/3984? show $=$ full

17. Anandan S, Dhaliwal GS, Huo Z, Chandrashekhara K, Apetre N, Iyyer N (2018) Curing of thick thermoset composite laminates: multiphysics modeling and experiments. Appl Compos Mater 25(5):1155-1168. https://doi.org/10.1007/s10443-017-9658-9

18. Dolkun D, Zhu W, Xu Q, Ke Y (2018) Optimization of cure profile for thick composite parts based on finite element analysis and genetic algorithm. J Compos Mater 52(28):3885-3894. https://doi. org $/ 10.1177 / 0021998318771458$

19. Heinze S, Echtermeyer AT (2018) A practical approach for data gathering for polymer cure simulations. Appl Sci 8(11):1-31. https://doi.org/10.3390/app8112227

20. Yuan $\mathrm{Z}$ et al (2018) Evolution of curing residual stresses in composite using multi-scale method. Compos Part B Eng 155:49-61. https://doi.org/10.1016/j.compositesb.2018.08.012

21. Zhang G, Wang J, Ni A (2019) Process-induced stress and deformation of variable- stiffness composite cylinders during curing. Materials (Basel) 12(2). https://doi.org/10.3390/ma12020259

22. Svanberg JM, Holmberg JA (2004) Prediction of shape distortions. Part I. FE-implementation of a path dependent constitutive model. Compos Part A Appl Sci Manuf 35(6):711-721. https://doi.org/10. 1016/j.compositesa.2004.02.005

23. Bogetti TA, Gillespie JW (1992) Process-induced stress and deformation in thick-section thermoset composite laminates. $J$ Compos Mater 26(5):626-660. https://doi.org/10.1177/ 002199839202600502

24. Shah DB, Patel KM, Patel AI, Pariyal V, Joshi SJ (2018) Experimental investigation on spring-back deformation during autoclave curing of parabolic antenna reflectors. Compos Part A Appl Sci Manuf 115:134-146. https://doi.org/10.1016/j.compositesa. 2018.09.017

25. Bosi F, Schlothauer A, Pellegrino S (2018) Cure-induced deformation of ultra-thin composite laminates. AIAA/ASCE/AHS/ASC Struct Struct Dyn Mater Conf 2018 (210049):1-10. https://doi. org/10.2514/6.2018-2241

26. Berdnikova NA, Belov OA, Lopatin AV (2019) Research and optimization of production cycle of high-precision composite spacecraft antenna reflector. Spacecrafts Technol:59-72. https:// doi.org/10.26732/2618-7957-2019-2-59-72

27. Weber TA, Arent JC, Münch L, Duhovic M, Balvers JM (2016) A fast method for the generation of boundary conditions for thermal autoclave simulation. Compos Part A Appl Sci Manuf 88:216-225. https://doi.org/10.1016/j.compositesa.2016.05.036

28. Bohne T, Frerich T, Jendrny J, Jürgens JP, Ploshikhin V (2018) Simulation and validation of air flow and heat transfer in an autoclave process for definition of thermal boundary conditions during curing of composite parts. J Compos Mater 52(12):1677-1687. https://doi.org/10.1177/0021998317729210

29. Dumont F, Fröhlingsdorf W, Weimer C (2013) Virtual autoclave implementation for improved composite part quality and productivity. Prog Orthod 15(1):277-289. https://doi.org/10.1007/s13272013-0072-1

30. Kamal MR, Sourour S (1973) Kinetics and thermal characterization of thermoset cure. Polym Eng Sci 13(1):59-64. https://doi.org/10. 1002/pen.760130110

31. Leroy E, Souid A, Sarda A, Deterre R (2013) A knowledge based approach for elastomer cure kinetic parameters estimation. Polym Test 32(1):9-14. https://doi.org/10.1016/j.polymertesting.2012.08. 012

32. DiBenedetto AT (1987) Prediction of the glass transition temperature of polymers: a model based on the principle of corresponding states. J Polym Sci Part B Polym Phys 25(9):1949-1969. https:// doi.org/10.1002/polb.1987.090250914

33. A A Johnston and A A Johnston, "An integrated model of the development of process-induced deformation in autoclave processing of composite structures by B . ScEng ., The University of New Brunswick, 1992 a thesis submitted in partial fulfillment of the requirements for the degree of DE," no. April, 1997.

34. Dai J, Xi S, Li D (2019) Numerical analysis of curing residual stress and deformation in thermosetting composite laminates with comparison between different constitutive models. Materials (Basel) 12(4). https://doi.org/10.3390/ma12040572

35. M Wenani, L Andersen, P Hørlyk, and M W Nielsen, "Prediction of process induced shape distortions and residual stresses in large with application to wind turbine blades," 2013

Publisher's note Springer Nature remains neutral with regard to jurisdictional claims in published maps and institutional affiliations. 